\title{
Student Teachers' Perceptions of Factors Influencing Learner Agency Working in Teams in a STEAM-Based Course
}

\author{
Youmen Chaaban ${ }^{1 *}$, Saba Qadhi ${ }^{2}$, Xiangyun Du ${ }^{1}$ \\ ${ }^{1}$ Educational Research Center College of Education Qatar University, QATAR \\ ${ }^{2}$ College of Education Qatar University, QATAR
}

Received 9 March 2021 - Accepted 18 May 2021

\begin{abstract}
The study adopted a sequential mixed-methods approach to investigate student teachers' learner agency in a teamwork setting at Qatar University. In the qualitative phase, a total of 10 student teachers enrolled in a course adopting a STEAM pedagogical approach participated in in-depth interviews. Qualitative analysis identified seven sources for practicing learner agency in teams. Using this data, the Learner Agency in Teamwork Settings survey was constructed. The survey was distributed to 108 student teachers taking the same course, which utilized an inquiry, problem solving, and digital-based learning design. Using exploratory and confirmatory factor analyses, four factors emerged, including: interest and motivation, teamwork self-efficacy, socio-cultural support, and team support. The findings have important educational implications for promoting student teachers' agency in similar educational contexts.
\end{abstract}

Keywords: learner agency, teamwork, STEAM, student teachers, teacher education, Qatar

\section{INTRODUCTION}

Teamwork has been effectively implemented to improve the quality of knowledge and skill acquisition in varying learning environments (Eteläpelto \& Lahti, 2008; Zhao \& Zheng, 2014), specifically in a STEAM context, which constitutes an interdisciplinary approach integrating Science, Technology, Engineering, the Arts, and Mathematics (Jho et al., 2016; Perignat \& KatzBuonincontro, 2019). Several studies have found students to engage productively in teams when they enact learner agency, defined as the ability to engage in purposeful actions, make choices, and exercise judgement that utilize the resources of the socio-cultural context (Campbell, 2012; Klemenčič, 2017). In a teamwork setting, enacting learner agency can translate into students' active participation in expressing their thoughts freely, responding to challenges, interacting with their peers, accomplishing team goals, and taking responsibility for the team's success (Ruys et al., 2010). These experiences offer students the opportunity to discover their personal strengths, interests and goals; develop positive attitudes and dispositions towards learning; and build identities as learners and as future professionals (Jaaskela et al., 2017; Zarraga-Rodriguez et al., 2015).

Despite the potential benefits of teamwork (Reeves et al., 2017), simply requiring student teachers to work in teams during their initial preparation programs does not guarantee high quality peer interactions or improved academic achievement, let alone transferability once they begin their teaching careers (Ruys et al., 2010). Previous studies have further revealed that many students lack agency to participate actively in teamwork projects (e.g., Jääskelä et al, 2017). Students have been found to avoid cognitive conflicts and negotiation of meaning, feel pressured by the emotional atmosphere and power relations of the team, and prefer individual tasks over teamwork (Fredrick, 2008; Ruiz-Ulloa \& Adams, 2004). Particularly in teacher education, Ruys et al. (2010) found that student teachers were rarely engaged in collaboration for their own learning, and then were not sufficiently prepared in the pedagogical uses of teamwork for their future classroom practices.

Recently, a growing number of studies involving student teachers have investigated the concept of agency in relation to taking a teacher leadership stance, renegotiating professional identities, and engaging in 


\section{Contribution to the literature}

- Examining learner agency as a complex construct affected by multiple factors using a sequential mixed methods approach.

- Identifying factors which either supported or hindered student teachers to enact agency working in teams in a STEAM context.

- Providing teacher educators with information on how to promote learner agency in the teamwork setting as they implement a STEAM approach in their courses.

the learning environment during teacher education (Chaaban \& Sawalhi, 2020, 2019; Ruohotie-Lyhty \& Moate, 2016; Toom et al., 2017). Yet, there is a dearth of studies about student teachers' perceptions of the factors influencing their learner agency in the teacher education context (e.g., Chaaban \& Sawalhi, 2020). Specifically, there has been no previous studies investigating their agency in teamwork-based courses adopting a STEAM pedagogical approach, despite the importance of learner agency in such constructivist learning environments (Klemenčič, 2017).

Therefore, the purpose of the current study was to investigate student teachers' perceptions of the factors that may influence their agency in a teamwork context. Particularly in this context, student teachers enrolled in a course adopting a STEAM pedagogical approach were required to work collaboratively to solve ill-structured and authentic problems within the teamwork setting. However, it was not clear whether they perceived this context to support their enactment of agency. Therefore, the sequential mixed methods study attempted to examine the factors influencing agency within teamwork settings from student teachers' perspectives. The study, thus, aimed to answer the following question: What are student teachers' perceptions of the factors that influence their enactment of learner agency in teams while taking a STEAM course?

\section{Teamwork in Higher Education}

Teamwork refers to a group of students working on interdependent tasks and sharing responsibilities and goals to reach a certain product or outcome within a predetermined period of time (Chapman et al., 2010). From a constructivist learning perspective, students' collaborative efforts become coordinated, synchronous and goal oriented, and are characterized by agentic participation, negotiation of meaning, co-construction of deep understanding, and the resolution of social conflicts (Borrego et al., 2013). Learning from this sociocultural approach is regarded as a collaborative meaning-making process, and knowledge is constructed rather than acquired (Eteläpelto \& Lahti, 2008). Therefore, students experience an interactive process of learning and reflection with their peers, while their instructors' role shifts from transmitting factual information to designing and facilitating learning
(Eteläpelto \& Lahti, 2008; Zarraga-Rodriguez et al., 2015).

Recent research documents the benefits of teamwork in supporting students' attainment of academic and professional goals (Borrego et al., 2013), in addition to improved self-satisfaction, enjoyment, and motivation (Chad, 2012; Du et al., 2019). Working in teams also presents students with the opportunity to learn a number of skills deemed necessary for their future professions, including the ability to negotiate peer authority, manage conflicts, solve ill-structured problems, and engage in productive dialogue (Chad, 2012; Chapman et al., 2010). As a result, many higher education institutions have acknowledged the importance of developing constructivist-based approaches for introducing teamwork into their classrooms (Ruiz-Ulloa \& Adams, 2004, p. 145). One such constructivist-based pedagogical approach is STEAM, which uses Science, Technology, Engineering, the Arts, and Mathematics as access points for guiding student inquiry, problem solving, and digital-based learning (Jho et al., 2016), with the aim of improving student engagement, creativity, innovation, and other cognitive benefits (Perignat \& Katz-Buonincontro, 2019).

Into the school and classroom context, teachers have long been pressured to collaborate in order to perform their jobs more successfully (Vangrieken et al., 2015). Several studies emphasize the necessity for teacher collaboration and the positive results for both teachers and their students (Jho et al., 2016). Specifically, both job satisfaction and self-efficacy have been positively correlated with the presence of a collaborative work environment (Reeves et al., 2017). Further, when teachers work together to implement innovative, student-centered and collaborative methods (Meirink et al., 2010; Reeves et al., 2017), the benefits of their collaboration translate into higher academic achievement results for their students (Lomos et al., 2011)

Yet, teachers have been found to lag behind other professionals when collaboration becomes the focus of discourse (Reeves et al., 2017; Ruys et al., 2010). Several studies reportedly note the resistance of teachers when they are required to collaborate (e.g., Meirink et al., 2010). Other studies note the challenges that hinder teacher collaboration, including the structural working conditions in schools, the prevalence of a culture of 
isolation, teachers' underlying beliefs, and norms of professional autonomy (Meirink et al., 2010; Reeves et al., 2017; Vangrieken et al., 2017). Therefore, it may be necessary to begin the shift towards collaboration during the initial preparation of teachers (Ruys et al., 2010). Teacher preparation programs are often considered a foundational context for student teachers to acquire these collaborative skills before they enter the profession (Rigelman \& Ruben, 2012).

\section{Conceptualizing Learner Agency}

Within the educational field, the concept of agency is considered a key construct in a constructivist learning environment, where students are offered opportunities for participation and influence (Jääskelä et al., 2017; Klemenčič, 2017). In such learning environments, students practice agency as they construct knowledge, use meta-cognitive and reflective processes, and engage in decision making and problem solving (Klemenčič, 2017). With this tradition in mind, learner agency can be defined as a student's actions and behaviors "to make free or independent choices, to engage in autonomous actions, and to exercise judgment in the interests of others and oneself" (Campbell, 2012, p. 183). Clearly, this definition underscores an individual's power, autonomy, and self-efficacy to engage in agentic choices and actions (Bandura, 2006). Accordingly, agency has been viewed in mostly positive terms, supporting individual's creativity, motivation, well-being, and selffulfillment (Eteläpelto et al., 2013).

In addition to this emphasis on the individual dimension, Jääskelä et al. (2017) noted that students do not enact agency in isolation, rather they participate and interact with their peers and teachers within sociocultural contexts. This tradition agrees with the notion that agency is practiced and manifested within a certain social and material context, which includes factors acting as either resources or hindrances (Eteläpelto et al., 2013). Agency can therefore be "achieved by individuals, through the interplay of personal capacities and the resources, affordances and constraints of the environment" (Priestley et al., 2015, p. 19). In other words, students' agency is constructed and manifested in constructivist learning environments that foster their capabilities to intervene in and influence their own and others' learning pathways (Klemenčič, 2017).

In adopting this notion of agency, the subjectcentered socio-cultural approach proposed by Eteläpelto et al. (2013) becomes relevant to the educational context. Inspired by this perspective, learner agency may be influenced by contextual factors, yet the interaction between the personal and the social, which are seen as 'closely interdependent and mutually constitutive' should also be considered (Eteläpelto et al., 2013, p. 59). Therefore, students' subjectivity and individuality are given sufficient attention, while acknowledging that their agentic actions and choices are mutually influenced by factors in their socio-cultural context, such as the emotional atmosphere and power relations of the participants (Jääskelä et al., 2017).

\section{Factors Influencing Learner Agency}

In line with the socio-cultural subject-centered approach, several personal and social-cultural factors may influence students' ability to practice agency, and thus are considered either resources or constraints to learner agency.

On the personal level, a key factor influencing agency is individuals' self-efficacy beliefs (Bandura, 2006). These beliefs act as sources of agency, enabling individuals to take responsibility of their learning, achieve higher outcomes, and persevere longer when confronted with challenges (Zimmerman \& Cleary, 2006). Another factor found to drive and support learner agency is motivation (Ryan \& Deci, 2000). Motivated learners are characterized as being driven by an inner impulse or desire that moves them towards accomplishing learning activities with a certain level of satisfaction and fulfilment (Pintrich et al., 1993). Specifically, when these activities are perceived as beneficial and interesting, students become actively involved in learning and direct their energies towards accomplishing the task (Ryan \& Deci, 2000). Other personal factors conceptualized by Jääskelä et al. (2017) include students' competence beliefs, which comprise their perceptions of having sufficient knowledge and skills to achieve desired goals, and thus having a sense of understanding and accomplishment. Lastly, participation activity is considered an influential factor of learner agency. Students' participation which conform to constructivist learning theories include participating in interactional learning situations, taking initiatives in discussions, and carrying responsibility for completing assigned tasks (Jääskelä et al., 2017).

Additionally, because agency can only be manifested in the interplay between the individual and the social context, several socio-cultural factors should be considered when exploring learner agency. Specifically in the teamwork environment, the enactment of agency is contingent on students' perceptions of the relational sources available. Therefore, peer support, trust, and a secure emotional environment are considered important factors influencing learner agency (Jääskelä et al., 2017). Other relational resources include students' confidence in their ability and in the ability of others to engage in productive conflict resolution, mature communication, role clarity, accountable interdependence, goal clarification, common purpose and psychological safety (Ruiz-Ulloa \& Adams, 2004). The socio-cultural context may further influence students' ability to enact agency. For instance, Zarraga-Rodriguez et al. (2015) identified a number of enabling contextual supports that determine team effectiveness. Particularly, they stressed the importance of a structured plan and vision, the provision 
Table 1. Participant demographics in qualitative phase

\begin{tabular}{lcccc}
\hline No. & Gender & Age & Nationality & Academic Year \\
\hline 1 & F & 32 & Qatari & First year \\
2 & F & 22 & Qatari & First year \\
3 & F & 21 & Qatari & First year \\
4 & F & 22 & Qatari & First year \\
5 & F & 28 & Qatari & Second year \\
6 & F & 23 & Qatari & First year \\
7 & F & 21 & Pakistani & Third year \\
8 & F & 22 & Bangladeshi & Third year \\
9 & F & 23 & Yemeni & First year \\
10 & F & 24 & Yemeni & Second year \\
\hline
\end{tabular}

of physical resources, training activities, conflict management and time management, and the provision of feedback, support and guidance based on predetermined evaluation criteria.

It may be reasonable to suggest that the development of students' agency begins with designing constructivist pedagogical approaches, such as a STEAM pedagogy, where students work together to solve ill-structured problems that have multiple valid solutions (Jho et al., 2016; Klemenčič, 2017). Students benefit from the opportunity to enact agency in such environments that foster active knowledge construction and collaborative problem-solving (Perignat \& Katz-Buonincontro, 2019). In line with this, Trede et al. (2012) claim that higher education institutions rarely provide students with the support for active agency, and consequently do not address the increasing pressure to prepare students for their future professions.

\section{Context of the Study}

The study was conducted at the only teacher preparation program in Qatar, and specifically in a course using a STEAM pedagogical approach focused on teaching reading and writing. The student teachers were taking this course as a core requirement of initial teacher preparation in a four-year program. Two authors designed the course based on the principles of STEAM pedagogy, which emphasized the integration and alignment of the content areas through inquiry-based and problem-based learning opportunities. Based on the belief that literacy should be an integral part of any discipline, they aimed to support student teachers' development of teaching and learning strategies suitable for K6 classrooms. Throughout the course, student teachers engaged in inquiry, problem solving, and digital-based learning, as key components of the STEAM approach. Accordingly, the major tenets of the course included students taking an active role in designing and presenting course material, and applying knowledge, research and collaborative skills to solve authentic problems. In accordance with these tenets, students were required to design a team presentation on STEAM approaches in association to literacy, investigate issues concerning reading and writing in Qatari government schools, propose viable solutions for these issues based on extensive research, and develop multiple lesson plans which incorporate STEAM approaches suitable for $\mathrm{K} 6$ classrooms.

\section{METHOD}

In the present study, a sequential mixed methods design was used to collect data in two phases. Creswell (2014) suggests that one viable reason for engaging in sequential mixed methods research is for the purpose of using qualitative data to inform the development of quantitative measurements, which would ultimately capture a more comprehensive understanding of the phenomenon, systematically and coherently. In the following sections, the qualitative phase is described, including the research design, participants, data collection and data analysis. This is followed by a thorough description of the quantitative phase. Noteworthy, the study was designed to meet the ethical specifications of Qatar University's IRB committee and protect the privacy of the participating student teachers.

\section{Qualitative Phase}

\section{Qualitative research design}

The qualitative phase of the study recognized participants as social actors whose perceptions and experiences were more important than the products and outcomes of the teamwork process. The qualitative phase focused on how students interpreted their experiences and constructed meanings from them within the context of the university classroom. Accordingly, ten student teachers were randomly chosen by the course instructor (Author 2) to participate in this phase of the study. The participants were provided with a consent form which explained the aims of the study, as well as the voluntarily basis of participation and withdrawal.

As displayed in Table 1, the majority of participants were mostly first year students. They were all females, consistent with the population of students enrolled in the teacher preparation program. Participants had different nationalities and their ages ranged between 21 and 32 years. 
Based on the theoretical framework alluding to the personal, relational, and contextual factors influencing learner agency, semi-structured interviews were developed and then used as a method of understanding participants' perceptions and experiences and as a way of promoting further reflection. Author 2 conducted the interviews with all participants individually during the Fall semester of the academic year 2019/2020. Following interview techniques suggested by Kvale and Brinkmann (2009), participants were invited to share their perceptions on teamwork generally and specifically in the STEAM course, their enactment of agency during the teamwork activities, including reference to planning, implementation, monitoring and reflection; and their perceptions of supportive and/or challenging factors. Probing and confirming questions were added, allowing participants to clarify, extend, and elaborate their initial answers. The interviews were conducted using a mix of English and Arabic according to the students' preferences, and lasted 30-40 minutes each.

Using audio-recorded transcriptions of the interviews, the data analysis procedure adopted included a deductive approach following a comprehensive literature review from the teamwork and agency fields respectively. Thus, a theory-driven analysis was conducted using the factors identified in the proposed theoretical framework, while special consideration was given to the personal and sociocultural factors which provided the resources or imposed certain constraints on practicing agency in teamwork settings. Several rounds of categorizing meanings from the data were conducted to examine the suitability of the theoretical framework to the aim of the current study (Kvale \& Brinkmann, 2009). The transcripts were thus annotated using the codes derived from the theoretical framework, which were found to be sufficient in this initial step. To ensure the theoretical framework was not imposed on the data, an inductive approach was used, allowing for the emergence of condensed meanings.

Throughout data analysis, Author 1 and 3 analyzed the interviews individually and then held several discussions of their analyses until agreement was met, while Author 2 provided comments and recommendations for further clarity and coherence. For this reason, the data underwent several rounds of comparing and contrasting established patterns and themes (e.g., differences between self-efficacy, competence beliefs, and participation activities), seeking disconfirming evidence (e.g., definitions of teamwork with teamwork challenges), and assigning representative quotations for reporting the themes (Miles, Huberman, \& Saldaña, 2014). This inductive process allowed for the explanation of the personal and socio-cultural factors in relation to the teamwork setting.

\section{Quantitative Phase}

\section{Quantitative research design}

Using the results of the qualitative analysis, the Learner Agency in Teamwork Settings survey was developed. Initially for each of the seven themes emerging from the qualitative phase, items were proposed based on the responses from the participants. Careful attention was given to representing each theme with an extensive list of potential items and then discussing the items thoroughly. Following this initial stage, a thorough literature review, including a number of surveys that assessed teamwork experiences and agency respectively were consulted (Eteläpelto \& Lahti, 2008; Jääskelä et al., 2017; Zarraga-Rodriguez et al., 2015). These surveys provided insight into items which were not initially generated or in the method of wording the items.

As with the development of any new survey, there was a need to pilot the survey to identify problem areas, redundancies and deficiencies in the instrument. A different sample of students $(\mathrm{N}=12)$ was asked to respond to the survey and report on the difficulty of the items and consistency of the constructs. While initially including 45 items, 4 items were considered redundant, and hence removed. Further, several items were reworded to make them easily understood by participants. The final version of the survey thus consisted of 41 items divided into the following constructs: interest and motivation $(8$ items, e.g., I have high motivation to study within a team), self-efficacy (4 items, e.g., I believe I can achieve the goals set for my team), competence beliefs ( 3 items, e.g., I think working in a team is easier than working alone), participation activities (7 items, e.g., I can participate easily in discussions in my team), peer support (7 items, e.g., I can ask for help from other students on my team when needed), trust (6 items, e.g., I feel that there is a supportive climate in my team), and contextual support (6 items, e.g., I receive ongoing feedback from my instructors about my work in teams).

The dimensions of interest and motivation, selfefficacy, competence beliefs and participation activities were intended to assess personal factors, while the dimensions of peer support, trust, and contextual support were intended to assess socio-cultural factors. The items on the survey were rated using a 5-point Likert scale $(1=$ strongly disagree to $5=$ strongly agree). The survey was distributed to all the students $(\mathrm{N}=112)$ taking the course during the final week of the Fall semester 2019/2020. A total of 108 student teachers consented to taking part in the survey by anonymously filling it in. The survey took approximately 30 minutes to complete using a pen and paper format.

An Exploratory Factor Analysis was deemed necessary in order to reduce the data to a smaller set of 


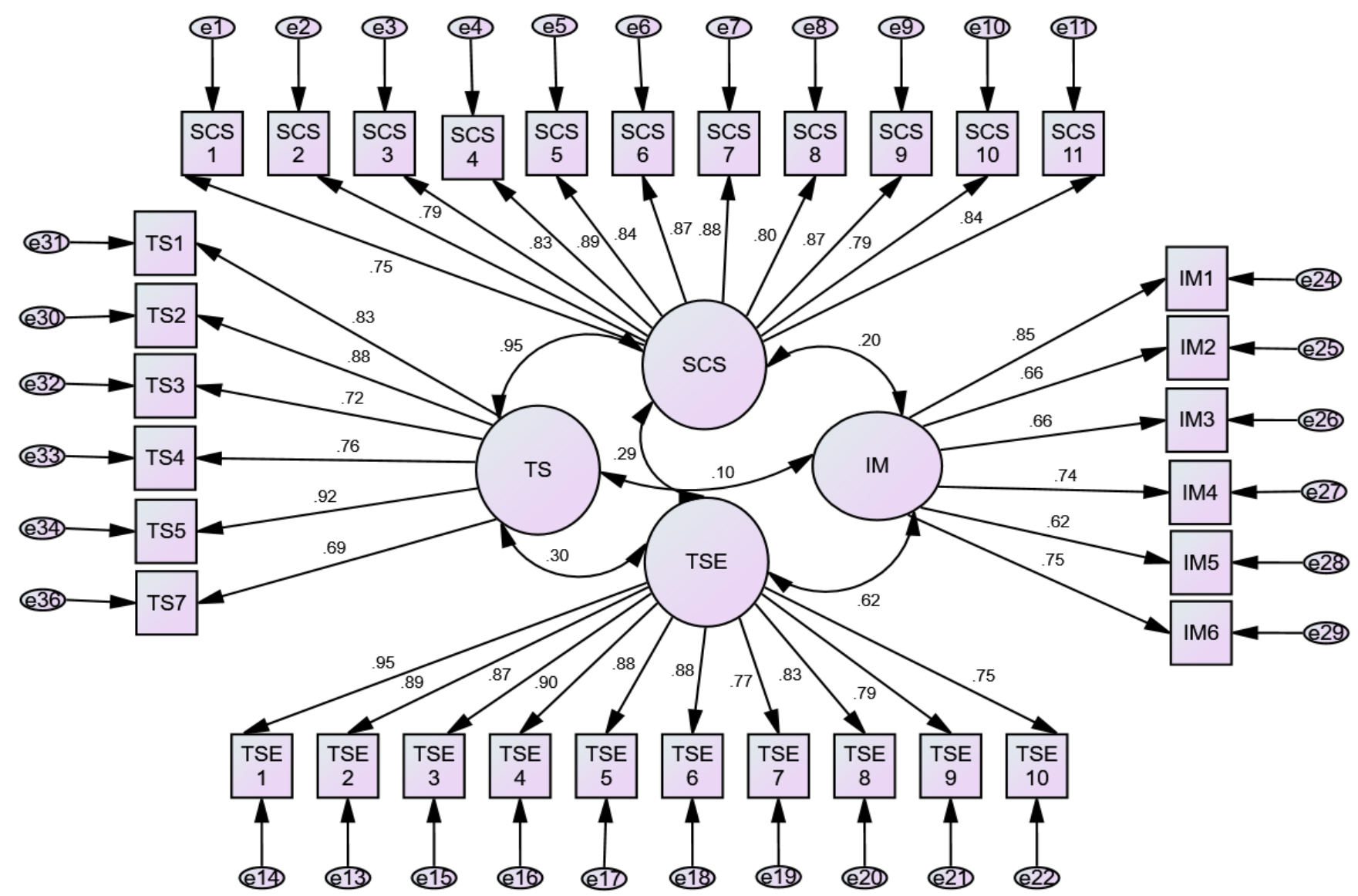

Figure 1. CFA for the four factors of survey using AMOS

manageable factors, as well as to isolate the items that did not measure the constructs well. Before attempting the EFA, the critical assumptions underlying factor analysis were verified by examining Kaiser-Meyer-Olkin $(\mathrm{KMO})$ for sampling adequacy $(=0.866)$ and Bartlett test of sphericity $(\mathrm{X} 2=3459, \mathrm{df}=820, \mathrm{p}<0.001)$. Then principal components analysis with Varimax rotation was used to extract factors based on the criterion of eigenvalue equal or greater than 1.00. After conducting the EFA, only items from the survey with factor loadings greater than 0.32 were retained, hence, one item was removed.

To further validate the resulting factors, a Confirmatory Factor Analysis (CFA) was performed using AMOS 24 (see Figure 1). The factor loadings for all the subcategories reported in Figure 1 were significant and exceeded the suggested cut-off level of 0.60 . Several fit indices were also calculated to provide information on the adequacy of the fitted model. The calculations indicated the following results: (1) chi square or $\chi^{2}=1.97$, which is $\leq 2$, (2) Adjusted Goodness of Fit Index or AGFI $=0.821$, which is $\geq 0.80$, (3) Comparative Fit Index or CFI $=0.916$, which is $\geq 0.90$, (4) Tucker-Lewis Index or $\mathrm{TIL}=0.913$, which is $\geq 0.90$, and (4) Root Mean Square Error of Approximation or RMSEA $=0.073$, which is $\leq$ 0.08 . Based on these results, it may be safe to conclude that the resulting CFA model presented the best fit to the data (Harrington, 2009).
The four identified factors were thus renamed based on the items retained for each factor, namely: teamwork self-efficacy (TSE), interest and motivation (IM), sociocultural support (SCS), and team support (TS). In order to estimate the reliability of each factor identified, Cronbach's coefficient alpha was computed and values above 0.70 were considered acceptable. Finally, descriptive statistics, including means and standard deviations, were generated to provide an overview of the distribution of responses.

\section{RESULTS}

In the following sections, the qualitative findings resulting from the analysis of the interview data are presented under seven themes, followed by the results of the quantitative phase.

\section{Qualitative Results}

Seven factors were found to influence student teachers' ability to enact agency in a teamwork setting, as shown in Table 2. This included making choices and taking actions influenced by personal and socio-cultural resources or limitations. Accordingly, participants revealed interest and motivation, self-efficacy, confidence beliefs, participation activity, peer support, trust, and contextual support as influencing factors of their agency. 
Table 2. Themes emerging from qualitative analysis and sample quotes

\begin{tabular}{lll}
\hline Themes & Description & Sample quote \\
\hline Theme 1: & When motivated, participants expended higher & "I like teamwork, when the team members are \\
Interest in and & levels of energy and effort towards the team, and & collaborative. I like to meet and work together... it is \\
motivation for & took active roles in its success. However, motivation easier that way, but I only object when there is someone \\
teamwork & was contingent upon all members carrying out their & negative on the team, who ruins it" (P9) \\
& responsibilities towards the team.
\end{tabular}

Theme 2: Self- With high self-efficacy beliefs, participants achieved efficacy their team goals and overcame the relational challenges they faced through their agentic actions and choices. Hence, they facilitated their own "When I put in all my effort, I know that I have done what I can towards my team... Of course there will be obstacles, and there will be consequences, but I will be satisfied" (P5)

Theme 3: $\quad$ Participants showed confidence as agentic learners From time to time, I check if I am reaching my goals, I Confidence in accomplishing required tasks, taking advantage of want to make sure that I have contributed to the other beliefs available resources, and retaining a positive attitude towards challenges. Hence, they revealed a strong sense of leadership and control.

team members and they are completing their tasks. I make sure we are all doing our tasks, and no one is struggling" (P4)

Theme 4: $\quad$ Participants revealed irregularities in the way teams Participation engaged in planning, implementation, monitoring tendencies and reflection activities. While the planning phase was considered the most collaborative, other phases were completed individually.

Theme 5: Peer Some participants had the opportunity to practice support agency when they experienced other students as resources for learning, and when they provided support for other students in challenging tasks. However, they noted many challenges hindering peer support.

"The planning is where most of the engagement happens. After that, everyone does the work on their own... that's when we discuss the most" (P3)

"Usually there is no time for reflection, because they usually submit their tasks last minute...so I just put things together and make sure that it is consistent" (P2)

"I have a professional relationship with the team members...I discuss with them and make sure they are all working well" (P8)

"We should all be communicating together and making sure we are reaching our goals, but that is not easy. One student may have completed her work and another didn't: how can we put the parts together and someone hasn't finished. Same thing for the presentation: We have to practice, there has to be organization, but there is no time... we are all under pressure to complete other assignment too" (P10)

Theme 6: While some participants ensured an encouraging Trust and supportive atmosphere for their team members, others described a stressful atmosphere; one where the power relations among team members hindered their ability to practice agency without feeling pressured.

"I prefer teamwork, because it strengthens the relationship among students" (P6)

"I prefer working alone because group work doesn't do justice to my work, not all students are able to work together. Sometimes one student does all the work, not all of them work, depending on whether they are cooperative or not. If they are not cooperative, there is no use of teamwork. Alone, I am able to show myself" (P7)

Theme 7:

Participants recognized the opportunity to make

"Usually we ask the instructor to give us detailed Contextual independent choices and take autonomous actions, feedback on our work. Even if we missed something support as well as receive feedback from the instructor of the course as factors influencing agency.

feedback is the most important thing" (P1)

\section{Interest in and motivation for teamwork}

Participants in the current study revealed an important factor for practicing agency manifested in their interest in and motivation for teamwork. Some participants $(\mathrm{N}=5)$ were found to expend higher levels of effort towards achieving the goals of the team when they possessed high levels of motivation. These participants took active roles in the success of their teams, often carrying the responsibility of the team leader who inspires, prods, and supports other team members. Despite their preference for teamwork, practicing agency in this setting was also contingent upon the motivation of all the team members. In this regard, the majority of participants $(\mathrm{N}=8)$ had experienced members who did not complete their assigned work, resulting in a diminished sense of agency, as one participant explained her preference and excitement for teamwork "when team members are collaborative" and objecting "when some students don't do their parts, and ruin it for the team (P9).

The other participants $(\mathrm{N}=5)$ clearly lacked interest in and motivation for teamwork, and consequently 
expended their effort in making sure the final product met their personal criteria for success, often resulting in taking over the assigned work and completing it independently. Several reasons justified their choices and actions, including their perceptions of teamwork doing "injustice" to their work; team members thinking differently, not contributing to the tasks, or procrastinating "till the last minute;" and individual grades negatively affected by the failure of the members to fulfil their work.

\section{Self-efficacy}

Having high self-efficacy beliefs, the majority of participants $(\mathrm{N}=7)$ were able to achieve their team goals and overcome the relational challenges they faced through their agentic actions and choices. These participants disregarded challenges as hindrances and persevered with a feeling of satisfaction and enjoyment. In fact, they called on the importance of teamwork as a way to accomplish difficult tasks and engage in reciprocal learning.

By contrast, a few participants $(\mathrm{N}=3)$ expressed low self-efficacy towards working efficiently in a teamwork setting, leading to their inability to facilitate their own learning and the learning of their team members. This led to feelings of frustration with other team members and dissatisfaction with the end result. Consequently, they noted completing the task on behalf of the other members, as noted by Participant 2: "I just fix their work and if I want them to learn, I show them the changes I made, and send them a copy of the final product."

\section{Confidence beliefs}

Drawing on the personal resource of confidence, the majority of participants $(\mathrm{N}=9)$ were able to recognize and overcome the limitations and challenges presented within the teamwork setting. Such competence thus appeared to be an important factor influencing agency, enabling these participants to make choices and take actions that resulted in successful outcomes for themselves and their team members. Furthermore, participating in the teamwork setting offered the opportunity to gain confidence and "become stronger" through the acquisition of knowledge and skills considered necessary for the future teaching and learning.

Specifically, participants revealed several instances which characterized their confidence as agentic learners. For example, participants revealed confidence in their ability to (1) accomplish required tasks despite the differences in their capabilities and experiences, (2) take advantage of available resources, such as using technology as a meeting tool (e.g., Google Docs and WhatsApp), and (3) retain a positive attitude towards challenges, including their ability to learn from them. Particularly in a teamwork setting, most of the participants $(\mathrm{N}=7)$ were able to suggest the course of action for their teams and have their ideas accepted by the other team members. In this sense, they revealed a strong sense of leadership, but also a greater sense of control over other team members. By contrast, few participants $(\mathrm{N}=2)$ noted the disadvantages of possessing too much confidence in one's abilities, to the extent that one team member overrides the others in the name of "supporting" them, as one participant noted that "having confidence is one thing, but doing everything is just wrong" (P9).

\section{Participation tendencies}

Student teacher's participation activities were considered the most tangible outcome resulting from enacting agency in a teamwork setting. In this respect, all the participants revealed irregularities in the way teams engaged in planning, implementation, monitoring and reflection activities. During the planning stage, the majority of participants $(\mathrm{N}=9)$ engaged in dividing the tasks and distributing the work amongst the team members. One participant noted the importance of this phase, stating: "the planning phase is when most of the team engagement happens, and this is where we discuss the most" (P 3).

Despite noting disparities in participation among team members, most participants $(\mathrm{N}=6)$ described the planning stage as constituting a major factor influencing agency among team members when compared to the phases of implementation, monitoring and reflection. After the planning phase, participants explained several challenges limiting their ability to practice agency within a teamwork setting. The most obvious limitation was the shift from a collaborative learning environment to one characterized by individuality during the implementation phase. As a result, the challenges included the difficulty in (1) finding time to meet and communicate, (2) constantly reminding team members to complete their work, (3) receiving low quality work from team members, (4) spending more time "fixing" team member's work, and (5) sometimes completing the work on behalf of team members who failed to "fulfil their responsibility towards the team" (P5). Participants further acknowledged the fact that "in general, there was no real teamwork" (P1), and the notion that "when each student does her part, she won't learn the parts completed by her team members; this is one of the disadvantages of teamwork" (P 9).

Further, participants rarely practiced agency during the monitoring phase, as these comments revealed: "I don't think about the progress of the team" (P5), "I never think about my team's effort" (P6), and "we never sat together to monitor our progress, we just submitted our work...we never evaluated our progress" (P8). The reflection phase also restricted the ability of participants to enact agency, as very few participants $(\mathrm{P}=2)$ noted 
engaging in reflection activities once the teamwork task was presented. Contrary to their actual participation tendencies, all participants were consistent in their definitions of teamwork, particularly in the importance of making choices and taking action consistently as a team throughout the four phases of teamwork (planning, implementation, monitoring and reflection).

\section{Peer support}

Student teachers had a significant opportunity to practice agency in a teamwork setting when they experienced other students as resources for learning, and when they provided support for other students in challenging tasks. In this respect, all participants acknowledged the importance of this factor in influencing the construction of a successful team. One participant described a successful team as "one where all students cooperate, distribute the work among each other, share ideas, communicate effectively, and accept each other's ideas" (P7).

Despite such beliefs, many participants $(\mathrm{N}=7)$ noted their difficulty in practicing agency with a clear lack of peer support in the teamwork setting. Several challenges were described, including the difficulty in "agreeing with other team members" (P1), "establishing respectful relationships" (P3), and "communicating together when we are all under pressure" (P10).

\section{Trust}

Enjoying trusting relationships among team members was considered an important factor influencing learner agency, as described by the participants in this study. On one hand, participants unanimously agreed that they felt "welcomed" in their teams (P6) and were encouraged to participate in team discussions, specifically during the planning phase. Some participants $(\mathrm{N}=6)$ also noted their ability to create a supportive atmosphere for their team members by making sure they "completed their work on time" (P4), "asked team members for feedback" (P3), "requested help from the team" (P10), and "offered help anytime the team needed it" (P9).

On the other hand, some participants $(\mathrm{N}=5)$ described a stressful atmosphere within the team, one where the power relations among team members hindered their ability to practice agency more freely and without feeling pressured. For instance, a clear lack of trust surfaced among team members, particularity for two reasons: (1) some students had negative experiences with team members in the past, as one participant noted: "there are always some team members who do not submit on time and procrastinate" (P8), and (2) some students had a personal issue with trust, as one participant stated: "I'm a very independent person, I can't depend on others, I just don't trust other people's work" (P2).

\section{Contextual support}

Within this socio-cultural context, all participants recognized the differing characteristics of the course in providing the opportunity to make independent choices (e.g., the final product) and take autonomous actions (e.g., hierarchy of team members). This was in contrast to "most of the education courses, since they require only individual work" (P2).

Another frequently cited contextual resource was the feedback provided by the instructor of the course. According to all participants, instructor feedback had the potential to encourage them to (1) sustain the effort team members extended in reaching their goals, (2) persist in response to challenges, specifically those related to relational problems, and (3) feel "gratitude" for the opportunity to "learn and grow" (P3). However, in some cases, negative feedback was seen as "unfair", specifically to those who received a lower grade because they "had to take responsibility for the students who failed to do well" (P9).

\section{Quantitative Results}

For each of these seven themes emerging from the qualitative phase, the Learner Agency in Teamwork Settings survey was developed and used to collect quantitative data from participating student teachers $(\mathrm{N}=108)$ in this phase. The factor loadings resulting from the EFA were based on the remaining 40 items which had loadings higher than 0.32. Initially, the results of the EFA resulted in 8 factors. Subsequently, factors 7 and 8 , consisting of 4 items, were deleted because the content of their items were not consistent. Further, factors 3 and 4 were merged, as were factors 5 and 6 due to the relative consistency of their items. As shown in Figure 1, the CFA supported the four-factor structure of the survey and led to a shorter instrument, with the deletion of three items $(14,21$, and 28) which scored less than 0.60 .

Thus, four factors termed teamwork self-efficacy, interest and motivation, socio-cultural support, and team support respectively, were obtained as revealed in Table 3.

Following the EFA and CFA, Cronbach's reliability coefficients were computed. These coefficients indicated moderate to high reliabilities for each construct, as revealed in Table 4.

The descriptive statistics for the final version of the survey were also computed. Ten items were retained for teamwork efficacy $(\mathrm{M}=4.56$; $\mathrm{SD}=0.07)$; six items were retained for interest and motivation $(\mathrm{M}=3.90$; $\mathrm{SD}=1.36)$; eleven items were retained for socio-cultural support $(\mathrm{M}=4.25$; $\mathrm{SD}=0.10)$; and six items were retained for team support $(\mathrm{M}=4.25 ; \mathrm{SD}=0.23)$, as revealed in Table 5 . In particular, the factor that received the lowest mean average was interest and motivation in comparison with the other three factors. It was also the factor which received the largest variation among participants. This 
Table 3. Factor loadings on four factors $(\mathrm{N}=108)$

\begin{tabular}{lcc}
\hline Items & \multicolumn{2}{c}{ EFA factor loadings } \\
\hline Teamwork self-efficacy (TSE) & F1 & F2 \\
18. I take responsibility for being an active participant in my team. & F4 \\
10. I believe I can successfully complete tasks in a team. & .864 \\
19. I can take initiative and collaborate actively in my team. & .854 \\
11. I believe I can make my team succeed. & .846 \\
12. I believe I can achieve the goals set for my team. & .832 \\
20. I believe in my abilities as a learner in a team in spite of challenges. & .801 \\
7. I can express my thoughts and views without being ridiculed in my team. & .798 \\
5. I continue working hard in a team even when I have to put in a lot of effort. & .762 \\
16. I have strong desire to make my team work well. & .714 \\
21. I can ask questions and make comments in my team. & .624 \\
\hline
\end{tabular}

Interest and motivation (IM)

6. I have strong desire to learn within a team.

1. I think working in a team is not inspiring for me. $\quad .750$

$\begin{array}{lr}\text { 3. I think working in a team is not beneficial. } & .737\end{array}$

2. I have high motivation to study within a team. $\quad .706$

15. I think working in a team is easier than working alone. $\quad .603$

$\begin{array}{lr}\text { 4. The tasks which I worked on in a team were interesting. } & .563\end{array}$

\section{Socio-cultural support (SCS)}

40. I receive ongoing feedback from my instructors about my work in teams.

41. I am offered training activities that help me acquire team skills. 650

34. I feel other students on my team are interested in my viewpoints. 564

35. I can be myself in my team.

39. I am provided with the necessary resources and materials to work with my team members. $\quad .553$

26. I can deal constructively with problems that arise with other students on my team. .530

30. I feel welcomed in my team.

31. I feel that there is a supportive climate in my team. 663

32. I feel encouraged to participate in discussions in my team. 660

36. I have the needed support and guidance from my instructors for my work in teams. 591

29. I think some students have stronger influence on the team.

Team support (TS)

22. I can challenge other students' ideas in my team.

25. I can ask for help from other students on my team when needed. .672

23. I think other students on my team are a resource for learning.

27. I can discuss problems openly with other students on my team.

24. I can provide support on challenging tasks for other students on my team. .559

33. I think other students on my team can do a good job.

Table 4. Cronbach reliability coefficients $(\mathrm{N}=108)$

\begin{tabular}{lccc}
\hline Factors & Items & No. of Items & Cronbach Alpha \\
\hline TSE & $5,7,9,10,11,12,16,18,19,20$ & 10 & 0.94 \\
IM & $1,2,3,4,6,15$ & 6 & 0.83 \\
SCS & $26,29,30,31,32,34,35,36,39,40,41$ & 11 & 0.90 \\
TS & $22,23,24,25,27,33$ & 6 & 0.80 \\
\hline Total & & 33 & 0.94 \\
\hline
\end{tabular}

Table 5. Means and standard deviation of the four factors $(\mathrm{N}=108)$

\begin{tabular}{lccc}
\hline Factors & Items & Mean & St dev \\
\hline TSE & $5,7,9,10,11,12,16,18,19,20$ & 4.56 & 0.07 \\
IM & $1,2,3,4,6,15$ & 3.90 & 1.36 \\
SCS & $26,29,30,31,32,34,35,36,39,40,41$ & 4.25 & 0.10 \\
TS & $22,23,24,25,27,33$ & 4.25 & 0.23 \\
\hline
\end{tabular}


result indicates the differences among participants in their preference for working within a teamwork setting. Despite such variations in interest and motivation, the result scored for teamwork self-efficacy was very high and quite consistent among all participants. This result translates into high perceptions in their abilities to make choices and take action that would lead to successful outcomes for the team.

\section{DISCUSSION}

The current study examined the factors that influenced student teachers' ability to practice learner agency in a teamwork-based course using a STEAM pedagogical approach. For one, the study revealed the intricacies inherent in the study of agency, and contributed to the literature pertaining to learner agency by providing a conceptual understanding of student teachers' agency in a teamwork setting. With no other study employing a sequential mixed methods design to study learner agency, the resulting survey aimed to encompass the theoretical structure of learner agency in a comprehensive manner by incorporating multiple sources of agency, both personal and socio-cultural. Consequently, the qualitative phase corroborated by the quantitative phase of the study confirmed the factors that influenced their learner agency. The validation process consisting of EFA followed by CFA confirmed that a 4-factor structure provided an acceptable conceptual foundation for identifying the sources of agency in teamwork settings.

Accordingly, participants revealed interest and motivation, self-efficacy, confidence beliefs, participation activity, peer support, trust, and contextual support as integrated factors influencing their agency from an analysis of qualitative data. These factors were further employed in the development of the Learner Agency in Teamwork Settings survey for use in the quantitative phase. The results of the EFA followed by CFA of the survey data led to the reconfiguration of several items in the initially developed constructs. A four-factor model emerged including teamwork selfefficacy, interest and motivation, team support, and socio-cultural support as significant resources for promoting student teachers' enactment of learner agency in a teamwork setting.

The findings are generally consistent with the patterns identified in previous studies, which regard learner agency as a complex, dynamic construct affected by multiple factors (Chaaban et al., 2021; Jääskelä et al., 2017). Findings further confirmed the dualistic nature of these factors in the way they may either act as resources enabling students to practice agency within a teamwork setting, or as obstacles hindering their agency (Jääskelä et al., 2017). Further, each of the factors identified in the current study corroborated with extant literature, specifically from the teamwork field (Chapman et al.,
2010; Zarraga-Rodriguez et al., 2015). In one study, the challenges students faced in a teamwork setting were behind their preference for individual tasks over teamwork (Du et al., 2019). Other studies (Hassanein, 2011; Rudawska, 2017) have further emphasized the importance of students' positive attitudes towards teamwork and the role played by fairness in this respect. Specifically, Du et al. (2019) found that the equal distribution of work and a fair evaluation were frequently cited concerns for engineering students in the Qatari context. Participants in the current study were divided in respect to their interest in and motivation for teamwork depending on these similar findings in the research.

Another important factor influencing student teachers' ability to enact learner agency in a teamwork setting was self-efficacy. Bandura (2006) describes selfefficacy as the foundation of agency. Student teachers' agency in the teamwork setting, as described in the current study, embodied their abilities to simultaneously facilitate their own learning, and the learning of the members on their teams. This finding confirms the results obtained in Toom et al.'s (2017) study in that student teachers' efficacy represents a core component of their agency, which paves the way for their ability to extend continuous efforts in the face of challenges until they satisfactorily reach their goals. The quantitative results further provided a more nuanced understanding of self-efficacy with the emergence of teamwork selfefficacy as a new factor consisting of items from selfefficacy, confidence beliefs, and participation tendencies. In this respect, the results were accepted as logical since by definition, self-efficacy constitutes a "teacher's belief in his or her capability to organize and execute courses of action required to successfully accomplish a specific teaching task in a particular context" (Tschannen-Moran et al., 1998, p. 233). Accordingly, student teachers' selfefficacy beliefs were directly connected to performing certain tasks, such as those required in a teamwork setting, as well as their confidence in their ability to accomplish those tasks.

One of the most controversial components of learner agency practiced in a teamwork setting was the factor of peer support. While it may be intuitive that peers act as significant resources for learning in a teamwork setting (Zarraga-Rodriguez et al., 2015), the current study also found peers to be inhibiting team member's ability to make choices and take actions that would lead to successful outcomes for the team. This finding confirms Väisänen et al.'s (2017) study which found student teachers capable of asking for help from peers and instructors, yet unable to offer support to their peers. In line with Toom et al. (2017), these results shed further light on the complexity of the social structure of the team, as well as the importance of social interactions among team members in providing the opportunity to practice agency. Specifically, the opportunities to 
contribute equally and actively in their teams, establish respectful relationships, and work interdependently on tasks are critical for student teachers' agentic learning.

Finally, interest in the concept of agency in educational research has been accompanied with an equally significant interest in the socio-cultural context of teacher education, where student teachers can be encouraged to participate in their immediate learning environment and become responsible for their own and other's learning (Ruohotie-Lyhty \& Moate, 2016). Among the most apparent socio-cultural factors influencing learner agency was the feedback received from the instructor throughout the team experience. This finding is consistent with other studies investigating the socio-cultural factors influencing teamwork effectiveness (Zarraga-Rodriguez et al., 2015). Additionally, the construct of trust from the original conceptualization of the factors influencing learner agency was found to merge with the socio-cultural support construct. This result was further accepted as logical as power relations and the emotional atmosphere may very well involve peers and instructors alike. In their study of student teacher collaboration, Eteläpelto and Lahti (2008) emphasize the importance of trust as an essential component of the socio-cultural environment. In their study, trust was conceptualized as feeling emotionally safe, enjoying compatible power relations with others, and having confidence in receiving support when needed. These aspects of the social environment can be provided by other team members, as well as instructors, who, according to Chapman et al. (2010) may bear negative perceptions towards their students' team dynamics, cohesion, trust, conflict, and conflict resolution abilities. Given the challenges of trust arising in the teamwork setting, instructors have been found to play a pivotal role in ensuring team solidarity and emotional safety, as well as levelling the ground of the power relations in the team (Fredrick, 2008).

\section{PRACTICAL IMPLICATIONS}

The primary implications address ways to promote student teachers' agentic experiences working in teams in a STEAM-based course. Essentially, the development of the Learner Agency in Teamwork Settings survey is considered pivotal for improving teamwork in teacher education. The survey responds to the need for considering learner agency as a prerequisite for effective teamwork. The study thus offers a tool for teacher educators to identify the factors that may either support or hinder the practice of agency in STEAM-based courses with a teamwork component, namely in association to literacy issues in K6 schooling. By capturing the resources and/or limitations of agency in a teamwork setting, teacher educators may be in a better position to recognize the strengths and weaknesses of the inquiry-based and problem-based learning tasks they assign, consequently supporting their student teachers to practice agency in the choices they make and actions they take.

Taking into account the different identified factors, teacher educators must play an active role in facilitating student teamwork. For one, instructors should become aware of the challenges students face in offering peer support and managing relational conflicts in teamwork. In this respect, they may carefully monitor social interactions and conversational patterns, thus intervening suitably when the need arises. Further, instructors must teach teamwork skills, and not rely on students' past experiences with teamwork. Such skills may include creating timelines, carrying out discussions, resolving conflicts, communicating openly, and making use of available technologies. These skills will be needed in their future teaching and learning contexts, as they work in collaborative teams with other in-service teachers, specifically for professional development activities.

As the student teachers clearly struggled to enact agency within the phases of teamwork, instructors should begin to critically question whether their assignments are structured in such a way that the process of teamwork is evident to their students. The starting point should be well-designed STEAM-tasks that highlight the necessity of setting goals and drafting a blueprint, the benefits of implementing the tasks with a sense of interdependency and togetherness, the importance of monitoring the team's progress towards goals, and finally the advantages of reflection if acquired skills are to be transferred to future teamwork settings.

According to the results of the study, fairness, especially in the distribution of grades and workload, is also an important source of learner agency. Teacher educators will need to clarify procedures and criteria for equity among team members before students begin. Rather than depending solely on instructor feedback, teacher educators can make good use of peerevaluations as a tool to assess student teams. They can use the peer evaluations in discussing the progress of the teams, which may reduce the number of students who take free rides or procrastinate.

These practical implications are by no means instantaneous solutions to all the challenges that student teachers may face during their agentic learning in a teamwork setting. Developing student teachers' agency requires extensive time and systematic examination of all the STEAM-based courses embedded with the teacher preparation program, such that instructors work harmoniously on designing their courses with compatible work-related goals. By simulating professional practices of teachers as networked experts (Jho et al., 2016), instructors may support the transferability of the skills acquired from practicing learner agency to their future teaching profession. 


\section{LIMITATIONS AND FUTURE DIRECTIONS}

The current study has been an attempt to examine the factors influencing learner agency in a teamwork setting. The survey offered as a tool for identifying the factors influencing learner agency during teamwork experiences was found to have high construct reliability. Despite these efforts, an obvious limitation was the sample size and representativeness. These limitations should be taken into consideration in the validation of the tool using different statistical analyses and by recruiting a larger sample size which includes both female and male respondents.

Further, the survey is a self-report instrument and student teachers may have responded in ways that did not reflect their authentic perceptions. Students may not always have the awareness and capability to correctly evaluate factors influencing their agency, as the study revealed several differences between the findings of the qualitative and quantitative analyses. Future attempts to use the survey should take into account the psychological state of the respondents. Administering the tool at the end of the STEAM-based course may conflict with students' concerns for final examinations and overdue assignments.

Lastly, caution was taken with regard to the generalizability of the sample, as the study was carried out in the context of one STEAM-bsed course within the teacher preparation program. Future studies using the survey as a data collection tool should ensure the sample is representative of different students, courses, and programs.

Despite the limitations of the study, it contributes significantly to the field by providing a robust theoretical framework of learner agency in a teamwork setting, and by offering a unique survey instrument which may be validated in the further exploration of this concept in other STEAM-based courses. The study provided empirical results for students' agentic experiences in a teamwork setting and the factors which they perceived influenced their learner agency. Future studies may benefit from this study's sequential mixed methods design by using in-depth interviews and the survey accompanied by focus group interviews with team members, recordings of team meetings, and written reflections.

\section{CONCLUSION}

The increasing demand for teachers who are able to work in teams and the challenges impeding teamwork in any setting led to the development of a STEAM-based course in which learner agency in a teamwork setting was a critical competence that should be fostered in student teachers. The fact that such agency is contingent upon multiple personal and socio-cultural factors stresses the common finding that effective teamwork practices are not simply learned by being a part of a team. The fundamentals of making independent choices and taking autonomous actions, while exercising judgement in the interest of oneself and others must be taught, practiced, and supported by a variety of teamwork opportunities throughout student teachers' preparation program. When student teachers are challenged and offered opportunities to practice learner agency in multiple teamwork settings, they are more likely to promote them in their work as teachers.

Author contributions: All authors have sufficiently contributed to the study, and agreed with the results and conclusions.

Funding: No funding source is reported for this study.

Declaration of interest: No conflict of interest is declared by authors.

\section{REFERENCES}

Bandura, A. (2006). Toward a psychology of human. Perspectives on Phycological Science, 1(2), 164-180.

Borrego, M., Karlin, J., McNair, L. D., \& Beddoes, K. (2013). Team effectiveness theory from industrial and organizational psychology applied to engineering student project teams: A research review. Journal of Engineering Education, 102(4), 472 512. https:/ / doi.org/10.1002/jee.20023

Campbell, E. (2012). Teacher agency in curriculum contexts. Curriculum Inquiry, 42(2), 183-190. https: / / doi.org/10.1111/j.1467-873X.2012.00593.x

Chaaban, Y., \& Sawalhi, R. (2020). The role of agency in the development of a teacher leadership stance among student teachers during the practicum experience. Research in Post-Compulsory Education, 25(2), 171-192. https://doi.org/10.1080/13596748. 2020.1742987

Chaaban, Y., Qadhi, S., \& Du, X. (2021). Student teachers' agency in the transition to emergency online learning. Research in Post-Compulsory Education, 26(2), 231-255. Chad, P. (2012). The Use of teambased learning as an approach to increased engagement and learning for marketing students: A case study. Journal of Marketing Education, 34(2), 128-139. https:/ / doi.org/10.1177/0273475312450388

Chapman, K. J., Meuter, M. L., Toy, D., \& Wright, L. K. (2010). Are student groups dysfunctional? Perspectives from both sides of the classroom. Journal of Marketing Education, 32(1), 39-49. https: / / doi.org/10.1177/0273475309335575

Creswell, J. W. (2014) Research design: Qualitative, quantitative, and mixed methods approaches (4th ed.). Sage.

Du, X., Ebead, U., Sabah, S., Ma, J., \& Naji, K. K. (2019). Engineering students' approaches to learning and views on collaboration: How do both evolve in a 
PBL environment and what are their contributing and contrasting factors? EURASIA Journal of Mathematics, Science and Technology Education, 15(11), em1774. https://doi.org/10.29333/ejmste/ 106197

Eteläpelto, A., \& Lahti, J. (2008). The resources and obstacles of creative collaboration in a long-term learning community. Thinking Skills and Creativity, 3, 226-240. https://doi.org/10.1016/j.tsc.2008.09. 003

Eteläpelto, A., Vähäsantanen, K., Hökkä, P., \& Paloniemi, S. (2013). What is agency? Conceptualizing professional agency at work. Educational Research Review, 10, 45-65. https:/ / doi.org/10.1016/j.edurev.2013.05.001

Fredrick, T. A. (2008). Facilitating better teamwork: Analyzing the challenges and strategies of classroom-based collaboration. Business Communication Quarterly, 71(4), 439-455. https:/ / doi.org/10.1177/1080569908325860

Harrington, D. (2009). Confirmatory factor analysis. Oxford University Press.

Hassanein, A. (2011). A qualitative student evaluation of group learning in higher education. Higher Education in Europe, 32(2/3), 135-150. https://doi.org/10.1080/03797720701840633

Jaäskelä, P., Poikkeus, A.M., Vasalampi, K., Valleala, U.M., \& Rasku-Puttonen, H. (2017). Assessing agency of university students: Validation of the AUS scale. Studies in Higher Education, 42(11), 20612079.

https:/ / doi.org/10.1080/03075079.2015.1130693

Jho, H., Hong, O., \& Song, J. (2016). An analysis of STEM/STEAM teacher education in Korea with a case study of two schools from a community of practice perspective. Eurasia Journal of Mathematics, Science \& Technology Education, 12(7), 1843-1862. https:/ / doi.org/10.12973/eurasia.2016.1538a

Klemenčič, M. (2017). From student engagement to student agency: Conceptual considerations of European policies on student-centered learning in higher education. Higher Education Policy, 30, 69-85.

Kvale, S., \& Brinkmann, S. (2009). Interview. Hans Reitzel.

Lomos, C., Hofman, R. H., \& Bosker, R. J. (2011). The relationship between departments as professional communities and student achievement in secondary schools. Teaching and Teacher Education, 27, 722-731. https:/ / doi.org/10.1016/j.tate.2010.12. 003

Meirink, J. A., Imants, J., Meijer, P. C., \& Verloop, N. (2010). Teacher learning and collaboration in innovative teams. Cambridge Journal of Education, 40(2), 161-181. https:// doi.org/10.1080/0305764X. 2010.481256
Miles, M., Huberman, A. M., and Saldaña, J. (2014). Qualitative data analysis: A methods sourcebook. Sage.

Pintrich, P.R., Smith, D., Garcia, T., and McKeachie, W. (1993). Predictive validity and reliability of the Motivated Strategies for Learning Questionnaire (MSLQ). Educational and Psychology Measurement, 53, 801-813. https:/ / doi.org/10.1177 / 0013164493053003024

Perignat, E., \& Katz-Buonincontro, J. (2019). STEAM in practice and research: An integrative literature review. Thinking Skills and Creativity, 31, 31-43. https:/ / doi.org/10.1016/j.tsc.2018.10.002

Priestley, M., Biesta, G., \& Robinson, S. (2015). Teacher agency: An ecological approach. Bloomsbury.

Reeves, P. M., Pun, W. H., \& Chung, K. S. (2017). Influence of teacher collaboration on job satisfaction and student achievement. Teaching and Teacher Education, 67, 227-236. https://doi.org/ $10.1016 / j$.tate.2017.06.016

Rigelman, N., \& Ruben, B. (2012). Creating foundations for collaboration in schools: Utilizing professional learning communities to support teacher candidate learning and visions of teaching. Teaching and Teacher Education, 28, 979-989. https://doi.org/ $10.1016 / j$.tate.2012.05.004

Rudawska, A. (2017). Students' team project experiences and their attitudes towards teamwork. Journal of Management and Business Administration, 25(1), 7897. https:// doi.org/10.7206/jmba.ce.2450-7814.190

Ruohotie-Lyhty, M., \& Moate, J. (2016). Who and how? Preservice teachers as active agents developing professional identities. Teaching and Teacher Education, 55, 318-327. https://doi.org/10.1016/ j.tate.2016.01.022

Ruiz-Ulloa, B. C., \& Adams, S. G. (2004). Attitude toward teamwork and effective teaming. Team Performance Management, 10(7/8), 145-151. https://doi.org/ $10.1108 / 13527590410569869$

Ruys, I., Van Keer, H., \& Aelterman, A. (2010). Collaborative learning in pre-service teacher education: an exploratory study on related conceptions, self-efficacy and implementation. Educational Studies, 36(5), 537-553. https:/ / doi.org/ 10.1080/03055691003729021

Ryan, R. M., \& Deci, E. L. (2000). Self-determination theory and the facilitation of intrinsic motivation, social development, and well-being. The American Psychologist, 55, 68-78. https://doi.org/10.1037/ 0003-066X.55.1.68

Toom, A., Pietarinen, J., Soini, T., \& Pyhältö, K. (2017). How does the learning environment in teacher education cultivate first year student teachers' sense of professional agency in the professional 
community? Teaching and Teacher Education, 63, 126136. https:/ / doi.org/10.1016/j.tate.2016.12.013

Trede, F., Macklin, R., \& Bridges, D. (2012). Professional identity development: a review of the higher education literature. Studies in Higher Education, 37(3), 365-384. https://doi.org/10.1080/03075079. 2010.521237

Tschannen-Moran, M., Woolfolk-Hoy, A., \& Hoy, W. K. (1998). Teacher efficacy: Its meaning and measure. Review of Educational Research, 68(2), 202-248.

Vaiisänen, S., Pietarinen, J., Pyhaltö, K., Toom, A., \& Soini, T. (2017). Social support as a contributor to student teachers' experienced well-being. Research Papers in Education, 32(1), 41-55. https://doi.org/ 10.1080/02671522.2015.1129643

Vangrieken, K., Dochy, F., Raes, E., \& Kyndt, E. (2015). Teacher collaboration: A systematic review. Educational Research Review, 15, 17-40. https:// doi.org/10.1016/j.edurev.2015.04.002
Zarraga-Rodriguez, M., Jaca, C., \& Viles, E. (2015). Enablers of team effectiveness in higher education Lecturers' and students' perceptions at an engineering school. Team Performance Management, 21(5/6), 274-292. https://doi.org/10.1108/TPM01-2015-0004

Zhao, K., \& Zheng, Y. (2014). Chinese Business English students' epistemological beliefs, self-regulated strategies, and collaboration in project-based learning. Asia-Pacific Education Researcher, 23(2), 273-286. https://doi.org/10.1007/s40299-0130103-z

Zimmerman, B. J., \& Cleary, T. J. (2006). Adolescents' development of personal agency. In F. Pajares \& T. Urdan (Eds.), Adolescence and education (Vol. 5): Selfefficacy beliefs of adolescents (pp. 45-69). Information Age.

\section{http://www.ejmste.com}

